\title{
Speed Limit Safety of Expressway Curves Based on the Critical State Evaluation Model of Vehicle Side Rollover
}

\author{
Zhongqing Xie ${ }^{1, *}$ \\ ${ }^{1}$ School of Transportation, Wuhan University of Technology, Wuhan 430063, China
}

Received 1 September 2017; Accepted 14 February 2018

\begin{abstract}
The design of a mountain expressway includes many special road sections, such as the combination of sharp bends and curved slopes, which may easily cause traffic accidents. Speed limit is an effective means of ensuring the safety of travellers. A novel speed limit formulation method was proposed in this study to improve the scientific level of the speed limit standard of a mountain expressway. First, the model of vehicle driving stability in the critical state of side rollover and sideslip was established. Second, the stabilities of vehicle side rollover and sideslip on the horizontal curve and slope curve were analyzed by considering the influence of vehicle dynamic characteristics. Finally, a specific speed limit implementation scheme for a multi-curve road section was proposed with an example. Results demonstrate that when the curvature radius of the road is large, the critical speed of vehicle side rollover and sideslip is high. In particular, the critical speed of vehicle side rollover is high when the gradient value of the transverse slope of the road section is considerable within a limited range. Meanwhile, the critical speed of vehicle sideslip is high when the frictional resistance coefficient of the pavement is high. The gradient value of the longitudinal slope of the curved slope section slightly affects the critical speed of vehicle rollover and sideslip. This study provides a strong theoretical basis for setting a safe driving speed limit in curve road sections.
\end{abstract}

Keywords: Critical state evaluation model of vehicle side rollover, Speed evaluation of a curve road, Vehicle dynamics, Speed limit strategy

\section{Introduction}

With its special geographical location, a mountain expressway contains many special sections, such as the combination of sharp bends and curved slopes that can easily cause major traffic accidents. Therefore, the study of mountain expressway safety has elicited considerable attention from relevant departments. The current background of the safety situation of mountain expressways is as follows $[1,2,3]$ :

(1) The special traffic conditions of the curve road sections of a mountain expressway may easily lead to side rollover accidents of large trucks.

(2) Speeding on a mountain expressway can easily lead to traffic accidents.

(3) The speed limit of existing expressway curves does not comprehensively consider driving behavior and characteristics, along with vehicle dynamics constraints.

At present, the main strategy for solving the safety problem of mountain expressways is to use reasonable speed limit values that can improve driving safety [3]. However, existing methods for determining speed limit values are mainly based on design speed and driving speed. Values are verified according to a certain evaluation technique until a

\footnotetext{
*E-mail address: zhqxiewhu+@sina.com

ISSN: 1791-2377 ( 2018 Eastern Macedonia and Thrace Institute of Technology. All rights reserved. doi:10.25103/jestr.111.13
}

reasonable driving speed is found. Although numerous achievements have been reported, certain aspects in previous studies are still not considered key research [1, 3, 4]. First, only a few studies have selected the curve road section of a mountain expressway as the main research object. Second, most studies on vehicle operating speed on mountain expressways have mainly focused on speed restriction or prediction, whereas studies on the safe driving speed of vehicles with side rollover accidents remain limited. Finally, research on vehicle driving stability that considers the two dangerous states of side rollover and sideslip is lacking. Therefore, the present study conducts explorations to enrich the research content of traffic safety on mountain expressways.

On the basis of the preceding analysis, a critical model of vehicle side rollover and a critical powertrain model of vehicle sideslip on the horizontal and slope curve sections are established based on the vehicle dynamics model using the speed limit formulation method of the critical state of vehicle side rollover. The relationships of the critical speed of vehicle side rollover and sideslip to the radius of the circular curve of a curve road, the gradient of a curve road section (transverse and longitudinal slope gradients), and the frictional resistance coefficient of pavement were analyzed. This study aims to accurately determine the speed limit value of a curve road section on a mountain expressway and to provide a theoretical basis and a reference method for improving the traffic safety level and efficiency of such section. 


\section{State of the art}

The curve road section of a mountain expressway includes multiple sections of the expressway where traffic accidents occur. Although the number of accidents on curve road sections is not the highest with respect to the total amount of traffic accidents, their consequences are serious and they can easily cause considerable loss of life and property. Domestic and foreign scholars have studied the speed limit safety of the curve road sections of mountain expressways for a long time, which is mainly reflected through the correlation analysis of vehicle speed and accident, and research on speed limit settings and the optimal speed limit method [3, 4].

Vehicle speed has long been considered one of the risk factors that affects traffic safety [4]. High vehicle speed has been proven to cause an increase in accident risk in a large number of studies. The relationship between driving speed and traffic safety shows that high speed increases the risk of accidents. When driving at high speed, drivers are likely to lose control of their vehicle and fail to predict a possible accident risk in a timely manner. In addition, when vehicle speed is high, the reaction of the driver takes a relatively long time, and vehicle distance after braking is also long. A large number of studies worldwide show that a strong correlation exists between speed and accident risk. The risks of accidents, injuries, and deaths are high with high speed, and a corresponding reduction in speed can effectively reduce damage probability $[5,6,7]$.

Solomony studied the relationship between the driving speed of vehicles on an expressway and the degree of casualties in traffic accidents [8]. The results showed that the probability of serious casualties is high in expressway accidents when driving speed considerably exceeds the speed limit. Bowie and Waltz discussed the relationship between speed characteristics during traffic accidents and the degree of casualties. The statistical analysis showed that the degree of casualties in traffic accidents was closely related to the speed change value when traffic accidents occurs. When the speed change value was less than $10 \mathrm{mph}$, the probability of moderate casualties or serious accidents does not exceed $5 \%$. When the speed change value was over $30 \mathrm{mph}$, the probability of moderate and serious traffic accidents was over $50 \%$. A correlation analysis model for average speed and accident safety was presented by Power [9]. The calculations and analyses showed that when the average speed on an expressway increased by $5 \%$, the number of accident casualties increased by $10 \%$ and the number of deaths increased by $20 \%$. The above studies proved that the number and intensity of road accidents and the probability of speed difference were related to average speed.

However, these studies have focused on speed limit safety on expressway curves. By contrast, quantitative studies on and references for the speed limit on mountain expressway curves remain limited.

Study on speed limit settings. The maximum driving speed on a road is determined through statutory speed restriction, which is one of the major strategies in road traffic management. In China, the "Road Traffic Safety Law of the People's Republic of China" and the "Regulations for the Implementation of Road Traffic Safety Law of the People's Republic of China" have formulated specific provisions in setting the maximum and minimum speed limit values for road traffic $[3,10]$. However, the maximum statutory speed limit is one of the early methods for setting the speed limit in expressways. The setting principle mainly considers the design speed of the road section, driving speed of vehicle, statistics of traffic accidents, and management factors. Certain types of roads exhibit good effects. However, the unified maximum statutory speed limit cannot be effectively adapted to diverse road conditions and types. Speed limit should be segmented according to the actual situation of road operation; that is, the speed limit value in a specific area should be determined based on full engineering investigation.

Data on the observed samples of road driving speed indicate that the lower limit for a road speed distribution that ranges above $70 \%$ is $16 \mathrm{~km} / \mathrm{h}$, whereas the upper limit is close to $85 \%$ of the vehicle speed on the road section. The discrepancy of the speed value on the road section and the probability of accidents decrease when the proportion of the speed value of a vehicle increases. Relevant studies show that the speed limit value on a regional section can be set to $85 \%$ of the vehicle speed at approximately $5 \mathrm{~km} / \mathrm{h}$. Simultaneously, this speed limit value is higher than the $67 \%$ vehicle speed on the section under the condition of free traffic flow. When the statutory speed limit value differs from the $85 \%$ vehicle speed by $3 \mathrm{~km} / \mathrm{h}$, the recommended vehicle speed on the regional section may not be provided. The Highway Scientific Research Institute of the Ministry of Communications of China has proposed the corresponding engineering technological methods for determining the speed limit value on a highway [11].

Many scholars have also presented optimal speed limit methods. Oppenlander [12] studied the method for determining the optimal speed limit on an expressway from the perspective of vehicle fuel consumption and emission, and other socioeconomic angles. It is found that when the driver controls a vehicle at a high speed, the probability of traffic accidents increases. Simultaneously, a high speed can increase fuel consumption and environmental pollution, thereby increasing the cost and risk of the entire driving process. Therefore, the optimal speed for individuals is not consistent with the comprehensive optimal speed for roads. The optimal speed limit is suitable for setting the overall optimal speed limit value for all types of roads. It is also applicable to the calculation of the regional speed limit value under specific traffic conditions. The difference $\Delta V_{85}$ of the average driving speed on adjacent roads is studied based on the evaluation method for operating speed coordination. The difference $\Delta V_{85}$ of the operating speed of adjacent sections indicates that $V_{85}$ is the most important influencing factor in determining the speed limit on an expressway. The Interactive Highway Safety Design Model provides a consistency module. The principle of this module is to use speed curve model to evaluate the consistency of road line design. Thus, the speed limit setting for the road line design can be consistent with the desired operating speed of the driver. Benthem [13] first proposed a research method that synthetically considers accident, passing efficiency, pollution, and public health to analyze the setting method for the optimal speed limit on an expressway. The system optimization was regarded as a model objective to present the optimal speed limit on an expressway. Similar research methods are also used to study the setting of the optimal speed limit on urban roads. The optimal control model can be proposed by comprehensively considering factors, such as accidents, passing time, and pollution, in social costs [14].

The present study summarizes the research results of the aforementioned literature. In the study of a reasonable speed limit for an expressway as the object, the main focus is on 
the engineering influencing factors of speed limit. Analysis and prediction models of traffic accidents are used as technical methods to evaluate the speed limit safety of an expressway. The three main shortcomings of the existing literature are as follows: (1) lack of a systematic analysis of the impact of speed limit value on traffic safety, (2) methods for evaluating speed limit safety are either limited or lacking, and (3) lack of a model for effectively describing the relationship between speed limit value and accident correlation.

To address the aforementioned shortcomings, the current study establishes a critical state evaluation model of vehicle side rollover according to vehicle dynamics. The model is mainly based on the side rollover accident data of curve road sections. The speed on a curve road is evaluated, and a theoretical basis for formulating a speed limit strategy for curve roads is provided.

A side rollover accident typically occurs when the vehicle body rotates around the longitudinal axis of the vehicle head at more than a certain angle of a moving vehicle. The large rotation angle can lead to the lateral movement of the vehicle body, which is unstable, and then the collision with the ground leads to dangerous traffic accidents. The factors that can cause side rollover accidents include the following: extremely high vehicle center of gravity, high speed, poor driving behavior, and low road friction coefficient. Speed driving is the main cause of vehicle side rollover and sideslip accidents in a mountain curve section. Therefore, the relationship between driving speed and driving stability (side rollover and sideslip) in the curve section of a mountain expressway is analyzed, and the impacts of road conditions in curve sections and different types of vehicle performance on driving safety are explored.

The vehicle driving stability model of the curve section is established by synthetically considering the influence of vehicle dynamic characteristics. The speed limit safety on the curve road section of a mountain expressway is studied.

The remainder of this study is organized as follows. The mechanical models are established in Section 3. In Section 4 , the actual road design parameter curve is considered an input, and the operating speed of a vehicle is determined to assess whether it exceeds the safety threshold value and whether the vehicle state is unstable by using engineering examples. The last section summarizes the paper and provides relevant conclusions.

\section{Methodology}

\subsection{Modeling the critical steady state of driving on the} horizontal curve section

The force analysis of the lateral motion state of a moving vehicle on a curve road is shown in Fig. 1. The lateral motion of the rigid body of the vehicle is modeled and analyzed without considering the influences of the suspension and tire deformation. The kinematic model of the side rollover of a moving vehicle on the curve can be established according to the relationship between lateral acceleration and driving speed. In Fig. 1, $\boldsymbol{F}_{\mathrm{z} 1}$ and $\boldsymbol{F}_{\mathrm{z} 0}$ represent the vertical reverse forces of the inside and outside wheels of the moving vehicle body, respectively. $\boldsymbol{F}_{\mathrm{y} 1}$ and $\boldsymbol{F}_{\mathrm{y} 0}$ indicate the adhesion between the inside and outside wheels of the vehicle body and the pavement, respectively. $\boldsymbol{a}_{\mathrm{y}}$ is the lateral acceleration, as shown in Fig. 1. The moment equation of rotation around the longitudinal axis of the vehicle head can be expressed as follows: $m \mathrm{a}_{\mathrm{y}} \cos \beta \mathrm{h}-\frac{1}{2} m \mathrm{a}_{\mathrm{y}} \sin \beta-m g h \sin \beta+F_{\mathrm{z} 1} B \cos \beta=0$

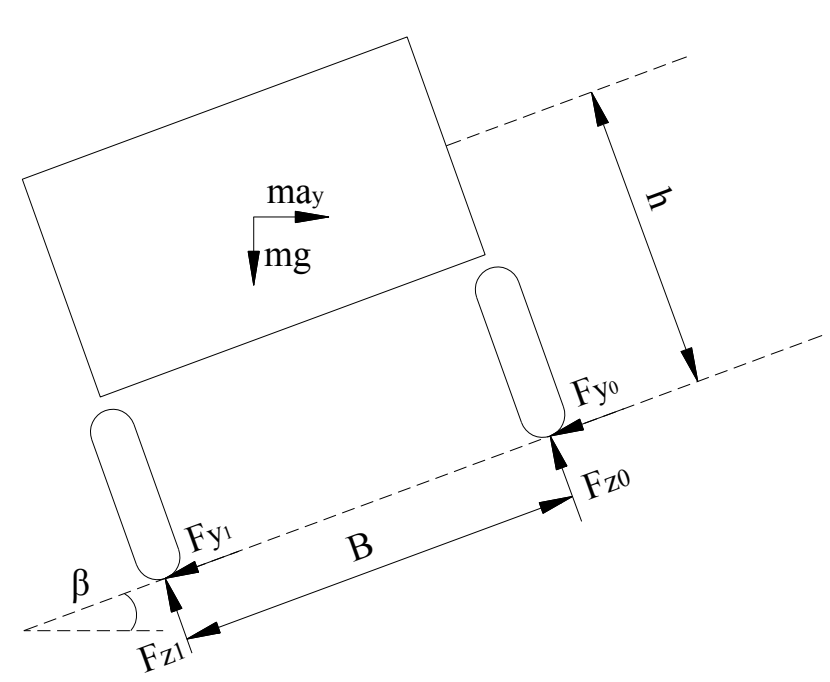

Fig. 1. Analysis of the lateral force of a moving vehicle on a curve road

where $\mathrm{m}$ is the mass of the vehicle, $\mathrm{g}$ is the gravitational acceleration coefficient $\left(9.8 \mathrm{~m} / \mathrm{s}^{2}\right.$ in the calculation $), \beta$ is the transverse slope gradient of the curved slope section, $\boldsymbol{h}$ is the height of the center of gravity of the vehicle dynamics, and $\boldsymbol{B}$ is the wheel track. The vertical reverse force of the inside wheels of the vehicle decreases as the lateral acceleration of the vehicle gradually increases. The vertical reverse force $\boldsymbol{F}_{\mathrm{z} 1}$ of the inside wheels of the vehicle body gradually becomes zero when the lateral force of the vehicle increases. Then, a side rollover accident will occur. The threshold value of the side rollover is deduced based on Eq. (1), as follows:

$$
a_{y}=\frac{h \sin \beta+\frac{1}{2} B \cos \beta}{h \cos \beta-\frac{1}{2} B \sin \beta} g
$$

Eq. (2) can be simplified as follows:

$$
a_{y}=\frac{2 h i+B}{2 h-B i} g
$$

where $i=\tan \beta$, and the threshold value of vehicle side rollover can be expressed as a function of the radius of the curve road and the driving speed of the vehicle, i.e.,

$$
a_{y}=\frac{v_{r}^{2}}{R}
$$

The critical speed of vehicle side rollover can be expressed based on Eqs. (3) and (4), as follows:

$$
v_{r}=\sqrt{\frac{2 h i+B}{2 h-B i} g R}
$$

The moving vehicle on the curved slope section sideslips when the transverse friction between the wheel and the pavement is greater than the transverse adhesion between the 
tile and the pavement. The tangential force and normal force of the vehicle on the road surface are established according to the principle of vehicle dynamics, as shown in Eqs. (6) and (7):

$$
\begin{aligned}
& m a_{y} \cos \beta=F_{y 1}+F_{y a}+m g \sin \beta \\
& m g \cos \beta+m a_{y} \sin \beta=F_{Z 1}+F_{Z a}
\end{aligned}
$$

The relationship between the adhesion of tire and pavement and the transverse friction resistance of tire and pavement can be expressed as the following equation when the phenomenon of sideslip occurs according to the principles of force balance and moment balance:

$$
\left(F_{Z 1}+F_{Z a}\right) \varphi=F_{y 1}+F_{y a}
$$

At this time, the lateral acceleration is as follows:

$a_{y}=\frac{\varphi g \cos \beta+g \sin \beta}{\cos \beta-\varphi \sin \beta}$

The expression for the critical driving speed of vehicle sideslip can be derived by combining Eqs. (9) and (5), as follows:

$v_{s}=\sqrt{\frac{\varphi g \cos \beta+g \sin \beta}{\cos \beta-\varphi \sin \beta}} R$

which can be simplified as:

$$
v_{s}=\sqrt{\frac{\varphi g+g i}{1-\varphi i} R}
$$

The directions of $\boldsymbol{F}_{\mathrm{y} 1}$ and $\boldsymbol{F}_{\mathrm{y} 0}$ are opposite to the direction shown in Fig. 1 when the vehicle exhibits a tendency to slide toward the inside of the road. At this time, the relation of the tangential force balance of the road becomes

$$
m a_{y} \cos \beta=m g \sin \beta-F_{y 1}-F_{y 0}
$$

In association with other relations, the expression for driving speed is derived when the vehicle sideslips toward the inside of the road, as follows:

$$
v_{s i}=\sqrt{\frac{\varphi g+g i}{1-\varphi i} R}
$$

where $\varphi$ represents the transverse frictional resistance coefficient of the tire and the pavement.

\subsection{Modeling the critical steady state of driving on the slope curve section}

Accident statistics show that sideslip accidents easily occur on downhill sections. The stability of moving vehicles on a slope road is further analyzed according to the dynamic model presented in Section 3.1. As shown in Fig. 2, assuming that the gradient angle of the longitudinal slope is $\alpha$, the moment equation of the vehicle head that rotates around the longitudinal axis can be expressed as follows:

$$
m a_{y} \cos \beta h-\frac{1}{2} m a_{y} B \sin \beta-m g h \cos \alpha \sin \beta+F_{Z 1} B-\frac{1}{2} m g B \cos \alpha \cos \beta=0
$$

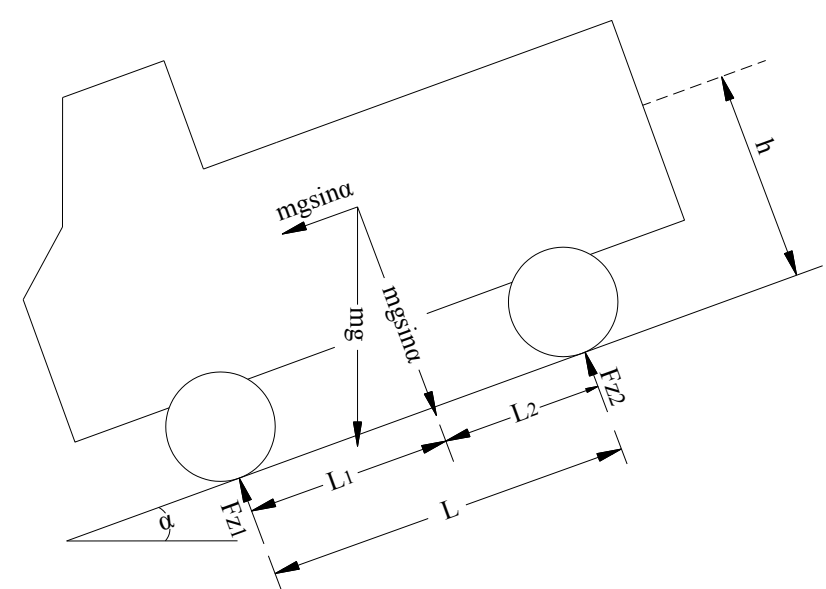

Fig. 2. Force analysis of the longitudinal section of a downhill vehicle

The critical speed of vehicle side rollover can be obtained at this time by following the same analysis:

$v_{r}=\sqrt{\frac{2 h i+B}{2 h-B i} g R \cos \alpha}$

The force balance relations of the tangential and normal directions of the slope road surface are established as follows:

$$
m a_{y} \cos \beta=F_{y 1}+F_{y a}+m g \cos \alpha \sin \beta
$$

$m g \cos \alpha \cos \beta+m a_{y} \sin \beta=F_{z 1}+F_{z a}$

The critical speed of vehicle sideslip can be obtained at this time by following the same analysis: 


$$
v_{s i}=\sqrt{\frac{\varphi g+g i}{1-\varphi i} R \cos \alpha}
$$

\section{Result analysis and discussion}

\subsection{Analysis of the driving stability of the vehicle on a horizontal curve}

In Section 3, the speed threshold values of vehicle side rollover and sideslip in the critical state were analyzed according to the principle of the vehicle dynamics. The driving speed threshold values of the vehicle can be calculated when the vehicle is in the critical state of side rollover and sideslip based on the dynamic model. The model can also be used to analyze the relationship between the speed values of the critical state of vehicle side rollover and sideslip and road curvature. Then, the speed threshold values during vehicle side rollover and sideslip accidents are analyzed according to the change in the linear parameters of the road. However, the accident speed threshold value calculated based on vehicle dynamics theory is higher than the actual speed value when vehicle side rollover and sideslip accidents occur. Therefore, in the actual speed limit design, the calculated value of the theoretical equation cannot be considered the reference value of the speed limit of the road. Structural features, such as the height of the center of mass and the wheel track of different types of vehicles, should be considered.

Table. 1. Wheel track and height of the center of mass of different types of vehicle (unit: $\mathrm{mm}$ )

\begin{tabular}{c|c|c}
\hline Types of vehicle & Height of the center of mass & Wheel track \\
\hline Sports car & $46-51$ & $127-154$ \\
\hline Minicar & $51-58$ & $127-154$ \\
\hline Limousine & $51-61$ & $154-165$ \\
\hline Light cargo bus & $76-89$ & $165-178$ \\
\hline Cargo bus & $76-102$ & $165-178$ \\
\hline Medium-duty truck & $114-140$ & $165-190$ \\
\hline Heavy-duty truck & $154-216$ & $178-183$ \\
\hline
\end{tabular}

\section{(1) Analysis of side rollover stability}

Table 1 shows the height of the center of mass and wheel track of several types of vehicle. The vehicle dynamics parameters (i.e., wheel track and height of the center of mass) of a heavy-duty truck are used as examples, and the relationship between the critical speed of vehicle side rollover and the horizontal curve radius is studied. The range of the transverse slope gradient value of the curve road section is set to $6 \%$ to $10 \%$ and the range of the super-high value is set to $6 \%$ to $10 \%$ according to the provisions of the "Technical Standard for Highway Engineering" (JTGB012014) $[15,16]$. A curve that describes the corresponding relationship between critical speed and the horizontal curve radius is plotted and used to reflect the relationship between the critical speed of vehicle side rollover and the line type of road given the various ranges of the parameters in Eq. (5). As shown in Fig. 3, the surface of the diagram reflects the relationship between the phenomenon of vehicle side rollover and the linear characteristics of a road section (i.e., transverse slope gradient, curvature radius). The correlation of the parameters on the surface shows that when the curvature radius of the road section gradually increases, the critical speed value of vehicle side rollover also gradually increases. However, the critical speed value of vehicle side rollover gradually increases when the transverse slope gradient value of the road section is limited to a certain range and when the super-high value of the gradient of the road section increases. The critical speed values of vehicle side rollover are calculated based on Eq. (5), and dynamic parameters, such as wheel track and height of the center of mass, are not considered. Therefore, the critical speed values of vehicle side rollover in Fig. 3 are higher than those in the actual situation.

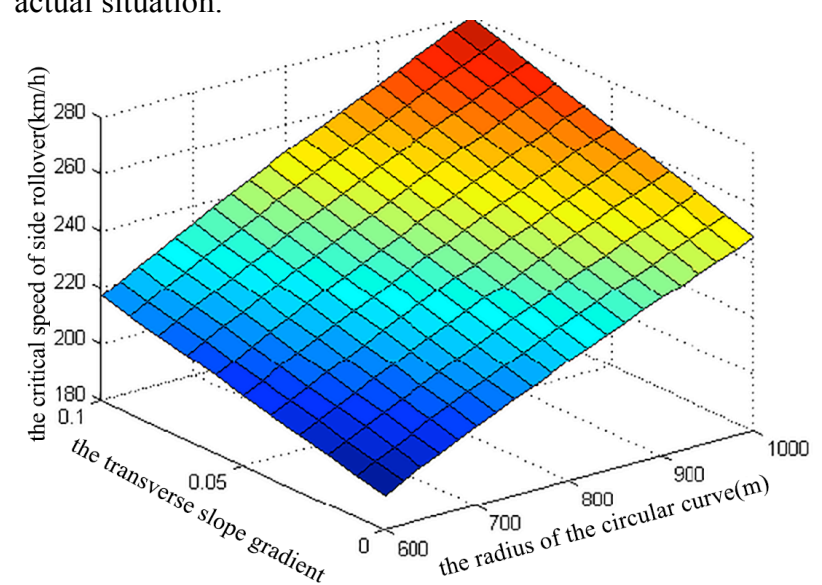

Fig. 3. Changing trend of the critical speed of vehicle side rollover on the curve section

\section{(2) Analysis of sideslip stability}

In this section, the relationships of the critical speed of vehicle sideslip to the radius of the curve road and the transverse friction resistance coefficient of the pavement and the tire in moving vehicles on the curve road are further analyzed. Eq. (13) (the super-high value is set to $6 \%$ in this section) is combined with the friction resistance coefficient of the pavement specified in the "Technical Specifications for Highway Engineering" (the cases of friction resistance coefficients ranging from 0.1 to 0.3 are analyzed in this section) to investigate the changing relationship between the critical speed threshold value of vehicle sideslip and the curvature radius of the road. The friction resistance coefficient of the pavement is shown in Fig. 4. The correlation of the parameters on the surface indicates that when the super-high value of the gradient is certain, the critical speed value of vehicle sideslip on the road section gradually increases with an increase in the transverse friction resistance coefficient of the road section. However, when the curvature radius of the road section increases, the critical speed value of vehicle sideslip also gradually increases. The changing trends of the parameters in Fig. 4 show that the decrease in the transverse friction resistance coefficient of the tire and the pavement and the decrease in the curvature radius of the road section can easily lead to vehicle sideslip.

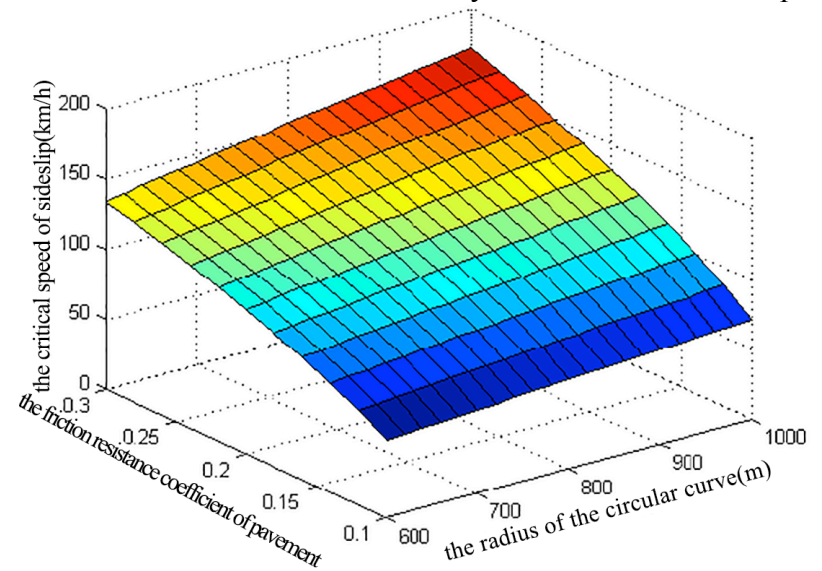

Fig. 4. Changing trend of the critical speed of vehicle sideslip on the curve section 
The linear characteristics of the road and the driving speed of the vehicle are important factors that cause the side rollover and sideslip of a vehicle. The curvature radius of the road, the friction resistance coefficient of the pavement, and the transverse slope gradient of the road section exhibit significant correlations with the critical speed of the vehicle when side rollover and sideslip occur. The probability of vehicle side rollover and sideslip decreases and the threshold value of safe driving speed increases when the curvature radius of the road section increases. For vehicle side rollover accidents, the threshold value of safe driving speed is high and the probability of vehicle side rollover is low when the value of the transverse slope gradient of the pavement is high within a limited range. For vehicle sideslip accidents, the threshold value of the critical speed of vehicle sideslip is low and the probability of vehicle sideslip is high when the adhesion coefficient of the tire and the pavement is low.

\subsection{Analysis of the driving stability of the vehicle on the slope curve}

Compared with the driving state of the vehicle on the horizontal curve section, the driving stability of the vehicle on the slope curve section should consider the influence of the longitudinal slope gradient.

\section{(1) Analysis of side rollover stability}

In this section, the correlations among the curvature radius of the slope road section, the gradient values of the longitudinal and transverse slopes, and the critical speed of vehicle side rollover are analyzed according to Eq. (15). The provisions of the "Technical Standard for Highway Engineering" (JTGB01-2014) state that when the design speed of an expressway section is $120 \mathrm{~km} / \mathrm{h}$, the maximum longitudinal slope gradient within the section should not exceed $3 \%$. The range of the longitudinal slope gradient is set to $0 \%$ to $10 \%$ and that of the transverse slope gradient is set to $6 \%$. The relationship between the critical speed of vehicle side rollover and the linear characteristics of a road is analyzed based on Eq. (15), as shown in Fig. 5. The correlation of the parameters on the surface shows that when the curvature radius of the road section gradually increases, the critical speed value of vehicle side rollover also gradually increases. However, the critical speed of vehicle side rollover is slightly influenced by the longitudinal slope gradient. The critical speed values of vehicle side rollover are calculated based on Eq. (15). Dynamic parameters, such as wheel track and height of the center of mass, are not considered. Therefore, the critical speed values of vehicle side rollover in Fig. 5 are higher than those in the actual situation.

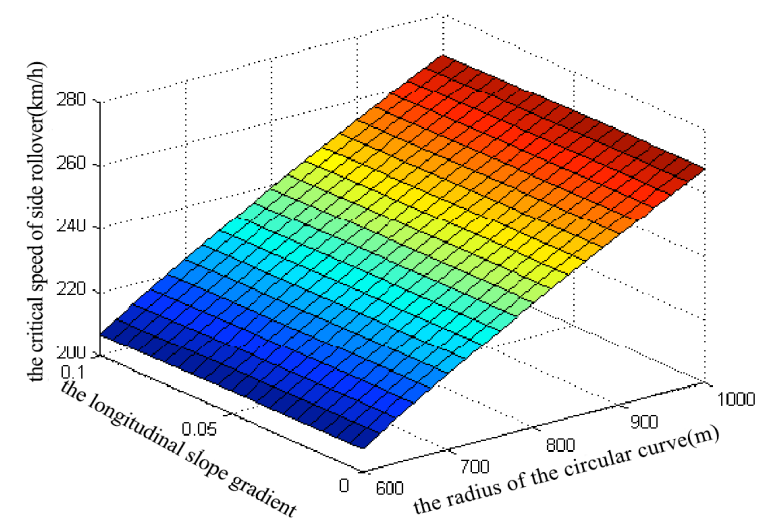

Fig. 5. Changing trend of the critical speed of vehicle side rollover on the slope curve section

\section{(2) Analysis of sideslip stability}

The influences of the gradient (longitudinal and transverse slope gradients) and the radius of circular curve on the critical speed of vehicle sideslip are analyzed according to Eq. (18). The changing relationships of the critical speed threshold value of vehicle sideslip to the longitudinal slope gradient and the friction resistance coefficient of the pavement are analyzed, as shown in Fig. 6. The values of the transverse slope gradient and the curvature radius of the road section are set to $6 \%$ and $600 \mathrm{~m}$, respectively. The correlation of the parameters on the surface shows that the critical speed of vehicle sideslip is evidently influenced by the friction resistance coefficient of the pavement and the tire, and the critical speed of vehicle sideslip increases with an increase in the friction resistance coefficient of the pavement. The threshold value of the steady speed of the critical sideslip decreases significantly when the frictional resistance coefficient is decreased. By contrast, the driving speed of the critical state of vehicle sideslip exhibits a decreasing trend with an increase in the longitudinal slope gradient. However, no evident relationship exists between this decreasing trend and the longitudinal slope gradient.

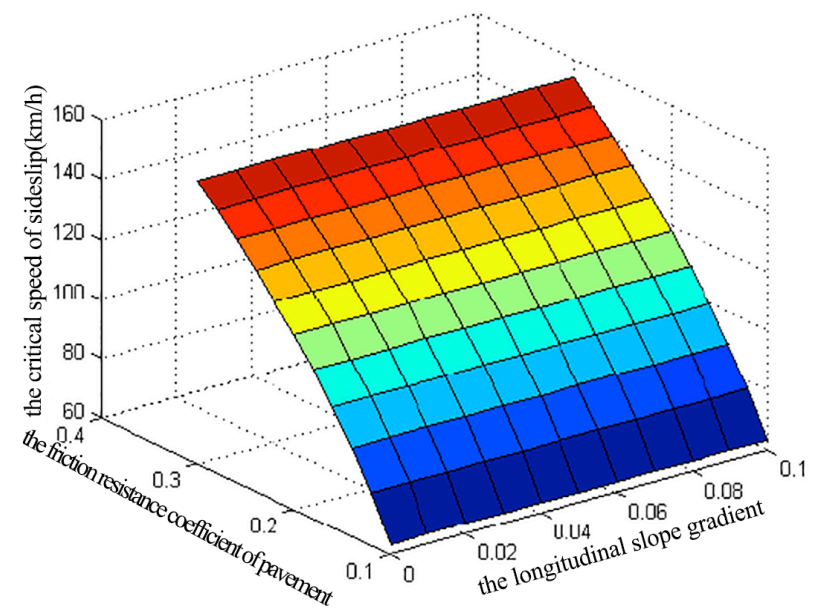

Fig. 6. Changing trend of the critical speed of vehicle sideslip on the slope curve section

As shown in the figure, the radius of the circular curve of a road is the most important factor that affects the driving stability of the vehicle (i.e., side rollover, sideslip). Moreover, the longitudinal slope gradient slightly affects the critical speed values of the vehicle side rollover and sideslip on the slope curve section.

The relationship between the critical speed of vehicle side rollover and sideslip and the radius of the circular curve of the road are analyzed through the curve relation model of relevant factors and steady driving speed. A theoretical basis for setting the safe driving speed of the curve road section is provided based on the results.

\subsection{Case analysis}

The speed limit scheme of the multi-curve highway section (Zhenning to Shengjingguan) on Hurui national road in Guizhou Province, China is considered the study object. The selected highway section (Zhenning to Shengjingguan) is a road with more curves on the main line, which significantly impacts traffic safety. The proposed method for evaluating the consistency of the comprehensive driving speed and the models of the driving stability of a vehicle provide a theoretical basis and a reference to improve the traffic safety 
level and efficiency of road sections. They are highly significant for the reasonable construction of road sections.

\section{(1) Evaluation of the consistency of driving speed}

The road is divided into several sections, and different driving speed values are set based on various linear characteristics, such as the gradient and curvature of road sections. The speed difference of the vehicle between adjacent sections is set to $\Delta V$. To ensure the continuity of the driving speed of vehicles in adjacent sections, the driver should control the vehicle as much as possible using a method of small speed difference in the same design section to improve the passing efficiency and safety of road traffic. The $85 \%$ speed of the vehicle on the investigation section is set to $\Delta V_{85}$, and that on the previous investigation section is set to $\Delta V_{85 i-1}$. The speed difference $\Delta V$ of the vehicle between adjacent sections is represented as $\Delta V=\Delta V_{85 i}-\Delta V_{85 i-1}$. The $85 \%$ driving speed difference between adjacent sections is used as the evaluation index of coordination of the road section speed design, i.e., $\Delta V_{85}$.

$\left|\Delta V_{85}\right| \leq 10 \mathrm{~km} / \mathrm{h}$ indicates that the consistency of the driving speed is very good.

$10<\left|\Delta V_{85}\right|<20 \mathrm{~km} / \mathrm{h}$ indicates that the consistency of the driving speed is generally good.

$\left|\Delta V_{85}\right| \geq 20 \mathrm{~km} / \mathrm{h}$ indicates that the consistency of the driving speed is poor, and the horizontal and longitudinal surface designs of adjacent sections should be readjusted.

(2) Evaluation of the coordination of driving speed and design speed

Table. 2. Speed limit standards of small passenger cars

\begin{tabular}{l|l|l|l|l|l}
$\begin{array}{l}\text { Serial } \\
\text { number }\end{array}$ & Edge of the road & $\begin{array}{l}\text { Starting point of the road } \\
\text { section }\end{array}$ & $\begin{array}{l}\text { Ending point of the road } \\
\text { section }\end{array}$ & $\begin{array}{l}\text { Length(km } \\
\text { ) }\end{array}$ & $\begin{array}{l}\text { Speed limit } \\
\text { standard(km/h) }\end{array}$ \\
\hline \multirow{2}{*}{1} & Right & K0+000 & K3+616 & 3.616 & 120 \\
& Left & K0+000 & K3+616 & 3.616 & 120 \\
\hline \multirow{2}{*}{2} & Right & K3+616 & K14+018 & 10.402 & 100 \\
& Left & K3+616 & K13+900 & 10.284 & 100 \\
\hline & Right & K14+018 & K40+220 & 26.202 & 80 \\
& Left & K13+900 & K40+266 & 26.366 & 80 \\
\hline
\end{tabular}

Table. 3. Speed limit standards of large trucks

\begin{tabular}{l|l|l|l|l|l}
\hline $\begin{array}{l}\text { Serial } \\
\text { number }\end{array}$ & Edge of the road & $\begin{array}{l}\text { Starting point of the road } \\
\text { section }\end{array}$ & $\begin{array}{l}\text { Ending point of the road } \\
\text { section }\end{array}$ & $\begin{array}{l}\text { Length(km } \\
\text { ) }\end{array}$ & $\begin{array}{l}\text { Speed limit } \\
\text { standard(km/h) }\end{array}$ \\
\hline \multirow{2}{*}{1} & Right & K0+000 & K3+616 & 3.616 \\
& Left & K0+000 & K3+616 & 3.616 \\
\hline \multirow{2}{*}{2} & Right & K3+616 & K14+018 & 100 \\
& Left & K3+616 & K13+900 & 100 \\
\hline \multirow{2}{*}{3} & Right & K14+018 & K40+220 & 80 \\
& Left & K13+900 & K40+266 & 26.202 \\
\hline
\end{tabular}

\section{Conclusions}

This study selected the curve road section on a mountain expressway as the research object and used statistical analysis and numerical simulation methods to investigate speeding behavior and to explore a method for formulating the speed limit on mountain road sections. The relationships of the critical speed of vehicle side rollover and sideslip to the radius of the circular curve of the road, the gradient of the curve road section (transverse and longitudinal slope gradients), and the frictional resistance coefficient of the pavement were analyzed. The following conclusions can be drawn.

(1) The radius of the circular curve is the most important factor that affects the driving stability of the vehicle (side
In this section, the coordination of the driving speed and design speed of the road section is evaluated by calculating and analyzing the driving speed and design speed differences on the same road section. When the difference between the driving speed and design speed on the same road section is greater than $20 \mathrm{~km} / \mathrm{h}$, the relevant technical indicators of the road section should be checked for safety according to the provisions in the "Guidelines."

The curve radius of the road section is used as the input to verify whether vehicle speed exceeds the critical value according to the evaluation model of the critical state of vehicle side rollover and sideslip. Through the synthetic comparison of the models of the consistency of driving speed and the stability of vehicle dynamics, several preliminary conclusions on the speed adjustment of the project are drawn as follows. On the road section from the starting point to Zhenning ( $\mathrm{K} 0+000 \sim \mathrm{K} 3+300)$, speed limit is not required. On the road section from Zhenning to Huangguoshu $(\mathrm{K} 0+000 \sim \mathrm{K} 3+300)$, the speed of small passenger cars and large trucks should be limited from 100 $\mathrm{km} / \mathrm{h}$ to $110 \mathrm{~km} / \mathrm{h}$. On the road section from Huangguoshu to Yongning (K13+400 YK40+398.709), the speed of small passenger cars and large trucks should be limited. The speed limit for small passenger cars is $80-90 \mathrm{~km} / \mathrm{h}$ and that for large trucks is $80 \mathrm{~km} / \mathrm{h}$.

The speed limit strategy, which is formulated by synthetically considering relevant factors such as traffic volume, natural environment, subgrade and pavement, and speed limit standards, is presented in the following table. 
vehicle during vehicle side rollover and sideslip in the mountainous areas were synthetically considered. However, vehicle type was only divided into small passenger cars and large trucks in this study. In the future, the safety of key operating vehicles should be considered by subdividing vehicle types. Meanwhile, studies that calibrate the effectiveness of vehicle speed calculated in theory remain limited. In the next step, relevant methods should be conducted through experiments. Relevant technologies, such as vehicle networks, should be integrated to establish the rule for vehicle speed under the linear conditions of different road sections. The effectiveness of the model should also be verified,which will have realistic engineering significance for improving the speed limit safety and stability of vehicles.

This is an Open Access article distributed under the terms of the Creative Commons Attribution Licence

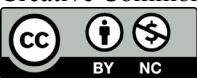

\section{References}

1. Wu, Y., Lu, Y., Li, F., Deng, Y. J., Peng, T. T., "Research on safety and speed-limit of oversize vehicle on expressway curve sections". Highway, 4, 2015, pp. 343-355.

2. Wen, H. Y., Luo, J., Li, J. H., "Safety state evaluation of freeway section in mountains based on PNN". Journal of South China University of Technology (Natural Science Edition), 39(8), 2011, pp. 113-117.

3. Zhu, Q. P., "Study on the safety operating speed and speed limit of freeway curve sections in mountain areas". Master thesis of South China University of Technology, China, 2014, pp. 21-25.

4. Traffic Administration Bureau of the Ministry of public security., "Annual report of China Road Traffic Accidents Statistics". Beijing: China communication press, China, 2002-2014, pp. 2-4.

5. Elvik, R., Vaa, T., "The handbook of road safety measures / edited by rune elvik, truls vaa". Injury Prevention, 12(1), 2004, pp. 63-64.

6. Taylor, M. C., Lynam, D. A., Baruya, A., "The effect of drivers' speed on the frequency of road accidents".Trl Report, 2000, pp. 3132.

7. Elvik, R., Vaa, T.,"The handbook of road safety measures". Elsevier, 12(1), 2004, pp. 63-64.

8. Aarts, L., Van, S. I., "Driving speed and the risk of road crashes: a review".Accident Analysis \& Prevention, 38(2), 2006, pp. 215-224.
9. UK Secretary of State for TransPort., "The Road Tunnel Safety Regulations 2007". London: The Stationery Office Limited, UK, 2007, pp. 8-10.

10. Transportation Research Board., "Managing speed: Review of the practice for setting and enforcing speed limits". Pittsburge: National Academic Press, America, 1998, pp. 253-259.

11. Wo Y., "Study on block-spots identification and operation". Master thesis of Wu Han University of Technology, China, 2007, pp. 2227.

12. Oppenlander, J., "Variables influencing spot-speed characteristics". Highway Research Board Special Report, 89, 1966, pp. 8-10.

13. Benthem, A. V., "What is the optimal speed limit on freeways?".Journal of Public Economics, 124, 2015, pp. 44-62.

14. Hosseinlou, M. H., Zolfaghari, A., Kheyrabadi, S. A. "Determining optimal speed based on air pollutants emission". International Congress on Structure, 39, 2014, pp. 36-41.

15. Li Y. W., Huo M., “'Technical Standard of Highway Engineering' (JTGB01-2014) Interpretation of new changes". China Highway, 23, 2014, pp. 54-56.

16. The CPC central committee for highway construction., "Technical Standard of Highway Engineering" (JTGB01-2014). Beijing: China communication press, China, 2014, pp. 5. 